\title{
An atypical case of secondary syphilis
}

\author{
J R WILLCOX
}

From the Academic Department of Genitourinary Medicine, Middlesex Hospital Medical School, London

SUMMARY A 27-year-old man with secondary syphilis had unusual cutaneous lesions of the ear. and scalp.

\section{Case report}

A 27-year-old exclusively heterosexual Caucasian male engineer (Mr R E) attended the department of genitourinary medicine as a result of contact tracing in August 1979. A male friend of $\mathrm{Mr} \mathrm{R} \mathrm{E}$ had developed primary syphilis after sexual intercourse with a mutual partner, Miss S C. She had also subsequently attended the department and been diagnosed as having secondary syphilis on the basis of generalised lymphadenopathy and widespread skin lesions.

\section{CLINICAL FINDINGS}

When Mr R E attended the clinic his only symptom was some small painless spots on his penis, which had been present for one or two days. There was a minute non-tender but indurated lesion on the frenulum and three superficial lesions on the glans penis, which were just visible to the naked eye. There was only slight inguinal lymphadenopathy.

On general examination no rash or oral lesions were present, but cervical lymphadenopathy and less marked enlargement of the axillary and epitrochlear glands were apparent. Two additional features were noted. Firstly, he had a deep non-indurated laceration $2.5 \mathrm{~cm}$ long in his scalp over the left frontal bone (fig 1) and, secondly, the tip of his left earlobe had a well demarcated purplish necrotic appearance, above which was a further area of erythema and desquamation (fig 2 ).

\section{SEXUAL HISTORY}

He admitted regular sexual intercourse over the preceding five weeks with his steady girl-friend (Miss J R) and on one occasion with Miss S C, the

Address for reprints: $\operatorname{Dr} \mathbf{J} \mathbf{R}$ Willcox, Special Treatment and Diagnostic Clinic, Plymouth General Hospital, Freedom Fields, Plymouth, Devon

Accepted for publication 28 June 1980 presumptive source contact, some six weeks. previously. He denied any past history of sexually transmitted disease.

On further questioning, Mr R E stated that the $\stackrel{\circ}{\leftrightharpoons}$ lesion on his ear had been present for about two months and he thought it was due to a "spot which $\Phi$ had turned septic." He could not explain the development of the scalp lesion, which had been present for at least a month and which, like the ear lesion, was painless.

\section{INVESTIGATIONS}

Dark-field microscopy of the lesions on the penis, earlobe, and scalp gave positive results for Treponema pallidum.

The Venereal Disease Research Laboratory (VDRL) test gave a positive result at a 1/32 dilution (1/64 on repeat specimen) as did the $T$ pallidum haemagglutination assay (TPHA).

\section{MANAGEMENT}

Mr R E was diagnosed as having atypical secondary of syphilis and was treated with procaine penicillin 600000 units intramuscularly daily for 10 days. $\mathrm{He}$ developed an influenza-like illness after his first $\delta$ injection consistent with a Jarisch-Herxheimer reaction. He did not reattend for follow-up until four $\mathrm{O}$ months after treatment, by which time physical examination was unremarkable except for a smallo area of alopecia over the original scalp lesion. Both his scalp and earlobe had healed within two weeks of of completing treatment.

\section{Discussion}

Although the inner ear can be affected in early syphilis, ${ }^{1}$ this appears to be the first reported case of $\stackrel{D}{D}$ a dark-field-positive lesion occurring on the earlobe, although there are reports that severe rupial lesions 0 can affect the auricle and canal and that papular lesions can affect the auricle. ${ }^{2}$ Furthermore, condylomata lata have been reported on the face. ${ }^{3}$ 


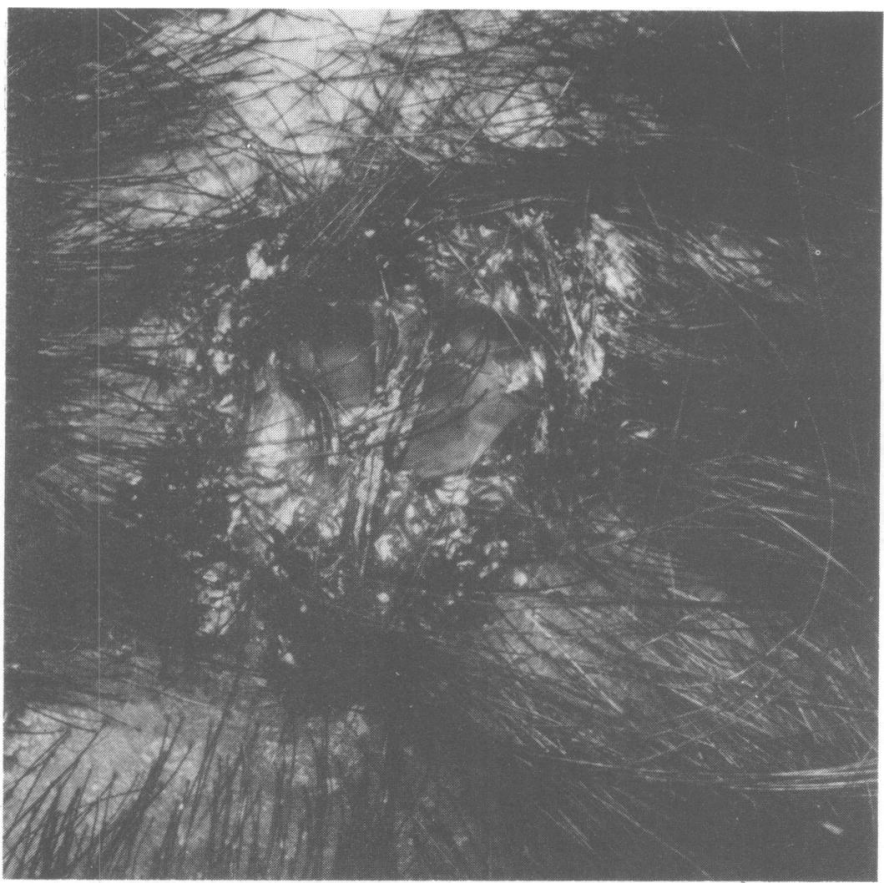

FIG 1 Deep non-indurated lesion of the scalp over left frontal bone.

FIG 2 Purplish necrotic lesion of the ear lobe with erythema and desquamation.

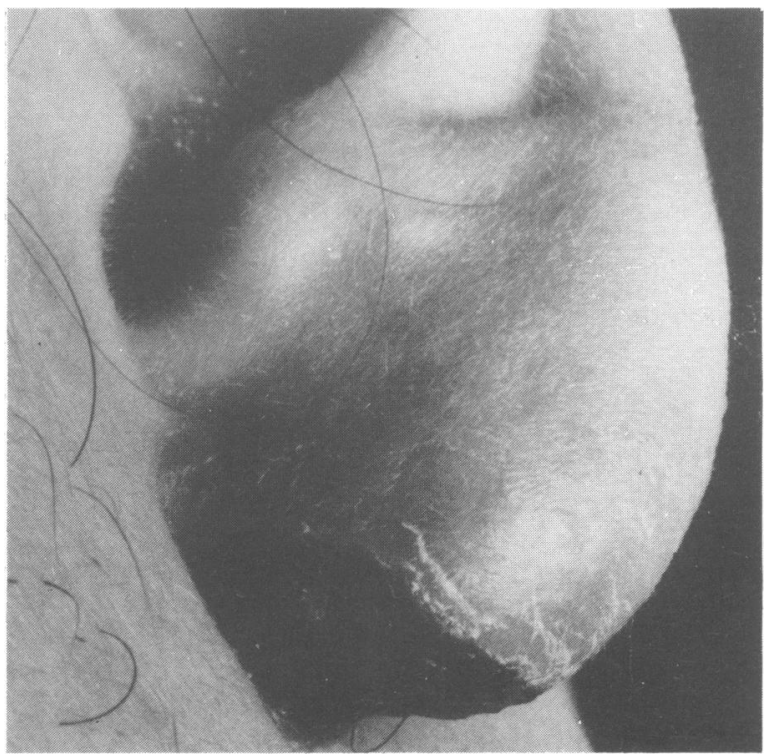

Secondary syphilis frequently affects the hair follicles of the scalp but Mr R E did not show evidence of this, and the scalp lesion-like that of the earlobe-was bizarre.

It should be pointed out that Mr R E thought his ear lesion had appeared before his single sexual contact with Miss S C. It is possible that he was mistaken in this, but it is also possible that he did indeed have a "spot" on his ear before the treponemal infection had developed. Alternatively, it is feasible that Miss $\mathbf{J} R$ and not Miss $\mathbf{S} C$ was the source contact, although he adamantly denied any 
other sexual partners except Miss S C and Miss $\mathbf{J} \mathbf{R}$ for six years. Miss $J$ R was examined on two occasions and showed no clinical evidence of treponemal infection, but VDRL tests showed a rise in titre from $1 / 32$ on her first visit to $1 / 128$ on her second. She was therefore diagnosed as having early latent syphilis.

It is interesting to postulate the reason for the predilection in site of Mr R E's lesions. Miss J R, the patient's girl-friend, was a hairdresser who regularly cut his hair and it was possible that local trauma (mechanical from scissors or heat from a hairdryer) might have modified the development of his lesions. Mr R E, however, did not use a hairdryer and was certain that he had not been injured in any way. He also denied any sexual practice, such as ear nibbling, which might have been contributory.
I would like to thank Dr R D Catterall for permission to report this case and also the photographic depart- on ment of the Middlesex Hospital.

\section{References}

1. Willcox RR, Goodwin PG. Nerve deafness in early syphilis. $\mathrm{Br}$ J Vener Dis 1971;47:401-6.

2. Stokes $\mathbf{J H}$, Beerman $\mathrm{H}$, Ingraham NR. Modern Clinical Syphilology. 3rd ed. Philadelphia and London: WB Saunders $\mathcal{C}$

3. Sehgal VN, Rege VL, Vadiraj SN. Condylomata lata of the face. Br J Vener Dis 1971;47:204-5. 